\title{
ERRATUM
}

\section{Adaptation of Enterococcus faecalis to Daptomycin Reveals an Ordered Progression to Resistance}

\section{Corwin Miller, Jiayi Kong, Truc T. Tran, Cesar A. Arias, Gerda Saxer, Yousif Shamoo}

Department of Biochemistry and Cell Biology, Rice University, Houston, Texas, USA; Department of Internal Medicine, Division of Infectious Disease, Laboratory for Antimicrobial Research, Houston, Texas, USA; Department of Microbiology and Molecular Genetics, University of Texas Medical School at Houston, Houston, Texas, USA Molecular Genetics and Antimicrobial Resistance Unit, Universidad El Bosque, Bogota, Colombia; Department of Ecology and Evolutionary Biology, Rice University, Houston, Texas, USA

Volume 57, no. 11, p 5373-5383, 2013. Page 5381: Figure 6 should appear as shown below.

A.

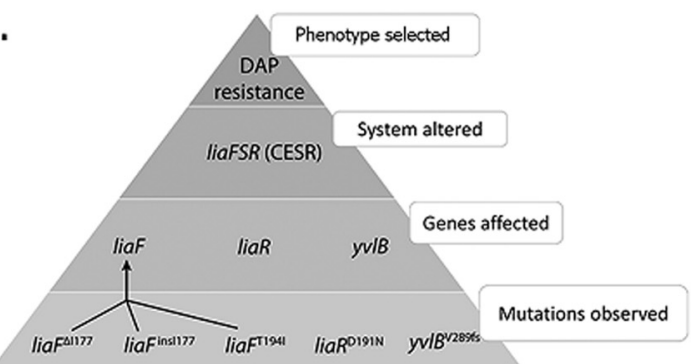

B. First Adaptive Response
liaFSR mutations first observed between Days 1-13
Observed in $94 \%$ of endpoint strains

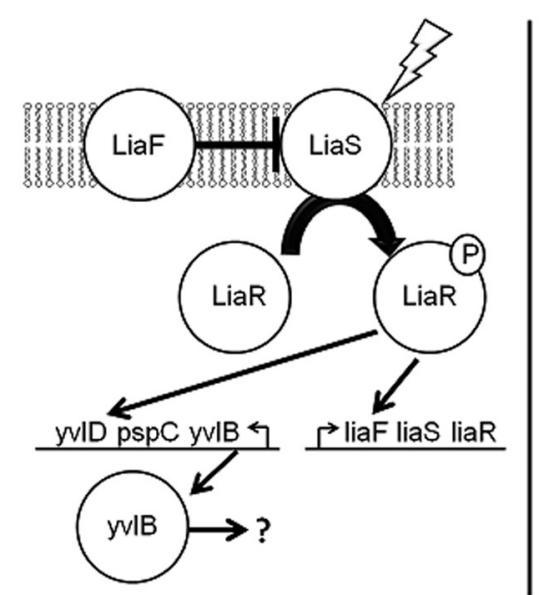

Second Adaptive Response Mutations first observed between Days 14-16 ds mutations observed in $46 \%$ of endpoint strains

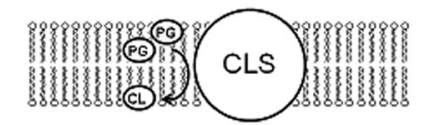

Cyclic dinucleotide signaling \& Glutathione synthesis Mutant wybT reaches $9 \%$ and gshF $12 \%$ by Day 23

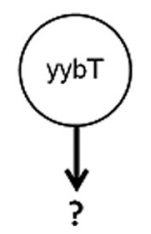

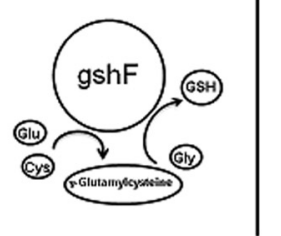

Third Adaptive Response

Mutations first observed between Days 22-23 $\operatorname{drmA}$ and $\mathrm{mdpA}<4 \%$ on Day 23

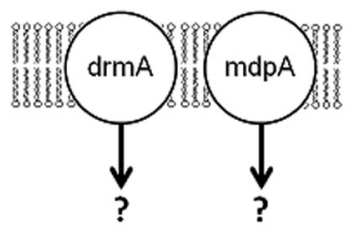

